\title{
Personality Characteristics of Dental Students in Relation to their Academic Performance
}

\author{
Afroza Hoque ${ }^{1}$, Iffat Ara ${ }^{2}$, Humayun Kabir Talukder ${ }^{3}$, Sakhawat Hossain ${ }^{4}$, Abu Rushid Md Mashrur ${ }^{5}$, \\ SMS Azad ${ }^{6}$, Md. Salahuddin ${ }^{7}$, N Akhter ${ }^{8}$
}

\begin{abstract}
This cross sectional descriptive study was carried out to explore the relationship between the personality variables and academic performance of dental student. The study population was dental students. Study was carried out at one government and three non-government dental colleges. Sample size was 200 and sampling technique was purposive. Data was collected by self administered structured questionnaire. Academic performance data for each respondent were collected throughout the one academic year ( $2^{\text {nd }}$ year) in dental students' files. It was measured by two term examination marks of four subjects based on 1 hour 30 minutes written exams. Personality of dental student was assessed through the Big Five Inventory (BFI). This wellestablished questionnaire was a 44-item measure of the Big Five personality factors: Extraversion, Agreeableness, Conscientiousness, Neuroticism, and Openness. The self administered items involve questions about typical behaviours or reactions, which was answered on a five-point Likert scale. This study revealed that there was no statistically significant relationship between student's personality characteristics and academic performance of dental students. Extraversion, neuroticism and openness had negative correlation with academic performance though it was not statistically significant. So, for better performance afore mention factors should be minimized as much as possible.
\end{abstract}

Key Words: Personality, Academic performance, Big Five Inventory, Extraversion, Agreeableness, Conscientiousness, Neuroticism, Openness.

\section{Introduction}

Besides cognitive abilities, a blend of personality characteristics is necessary for people to be successful in dental studies and eventually in the dental profession. Personality consists of an individual's native traits modified or accentuated by his training and environment. Personality is the result of the traits he possesses at birth plus his experiences through life ${ }^{1}$.

Understanding the reasons for individual differences in levels of scholastic achievement has always been a concern of educational psychologists. Knowledge of the factors that influence academic success has important implications for learning and education. Many educators, for example, are interested in knowing beforehand who will perform well, and who will perform poorly, in academic programs. Other researchers are concerned with identifying the determinants of academic success in an effort to

\footnotetext{
${ }^{1}$ Lecturer Dental Pharmacology, Pioneer Dental College;

${ }^{2}$ Associate Professor Department of Gynaecology \& Obstetrics, Dhaka medical college;

${ }^{3}$ Associated Professor (Teaching methodology) \& Course Coordinator, Center for Medical Education (CME);

${ }^{4}$ Professor of neurology, CME;

${ }^{5}$ Dental surgeon Upazilla health complex, Patiya, Chittagong;

${ }^{6}$ Assistant Professor of Science of Dental Material, Mandy

Dental

college.

${ }^{7}$ Assistant Professor of ENT

8 Assistant professor Gyane \& Obs, SSMC
}

Address of correspondence: Dr. Afroza hoque, Lecturer of Dental Pharmacology, Pioneer Dental College, Dhaka.

develop curricula aimed at improving levels of academic performance. ${ }^{2}$

Walton, (1987) stated during personality tests attitudes and values are taken into account, they have been shown to forecast better how students are likely to perform during the clinical years, than do measures of intellectual ability alone. Walton reported that he challenge at entry to medical school is for selectors to determine the best combination of personality tests and interest and attitude inventories for the investigation of professional competence at medical school and in later professional life. ${ }^{3}$ Researchers have supported and denied . ${ }^{4-9}$

Researchers have consistently attempted to understand the major predictors of individual academic performance of students. Previous findings suggest that specific variables of individuals such as personality and intelligence can be used to explain variance in academic performance. Among these 'non-intellectual' factors, several personality traits such as, openness to experience, extroversion and neuroticism are consistently reported to be associated with academic performance of students. Better academic performance by introverts has been attributed to their greater ability to consolidate learning, lower distractibility, and better study habits. These findings are corroborated by the fact that the extroverts under-perform academically owing to their distractibility, sociability, and impulsiveness. 
The negative relationship between academic achievement and neuroticism has usually been explained in terms of their higher stress and anxiety under examination conditions. ${ }^{10}$

The academic performances of the students are assessed by various tools and at different levels. In this study using written score of formative assessment that was term-I and term-II of student. The aim of the present study was to explore the relationship between personality and the academic performances. This study assessed the usefulness of Big Five Inventory (BFI) short phrases, 44 items ${ }^{11}$ in identifying personality variables and relation to academic performance of dental students.

\section{Methods \& Material}

This cross sectional descriptive study was carried out among the 200 dental students of one government and three non-government dental colleges. Sampling methods was purposive. Data was collected from the students with a self administered structured questionnaire with Bengali version. Personality characteristic data was collected from the second year student through self administered questionnaire. Academic performance data of dental students were collected from the teacher of four subjects. Only written marks were collected. Total marks were obtaining 200 marks. Collected questionnaire was edited, coded manually and entered into SPSS version 11.5 for analysis. Analysis was done by frequency table and Pearson correlation for significant test to see the relationship between academic performance and personality of the respondent and Pearson chisquare test was done to see the association of personality five factors and gender.

\section{Result}

Fig-1 shows majority percent were female $67 \%$ and Fig-2 and fig-3 showed that majority percent (57.3\% in term-I and $50.5 \%$ in term-II) student was poor performer in written exam.

Table 1-5 shows frequency distribution of item of personality five factors

Table 6 shows correlation of personality types with academic performances in two terms. Negative correlations of extraversion scale $(r=-0.107, \&$ $0.103 ; p=0.134 \& 0.150)$, positive correlations of Agreeableness $(r=0.046,0.034 ; p=0.523 \&$ 0.639), positive correlation between Conscientiousness and their both term examination score $(r=0.091 \& 0.112 ; p=0.202$ and 0.117$)$, negative correlation between Openness and term examination score $(r=-0.084 \&-0.077 ; p=0.236$ and 0.284)

Table7 contingency table of male and female were made then Pearson chi-square test was done

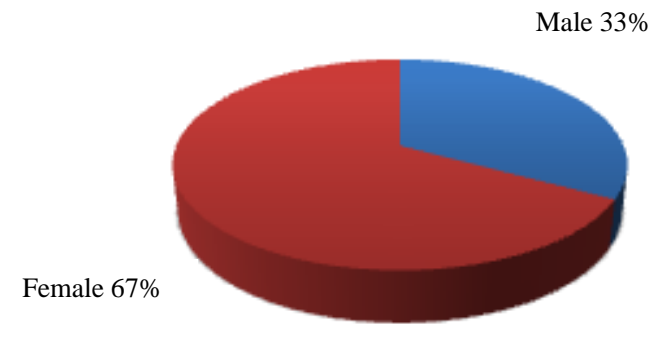

Fig-1. Gender distribution of respondent

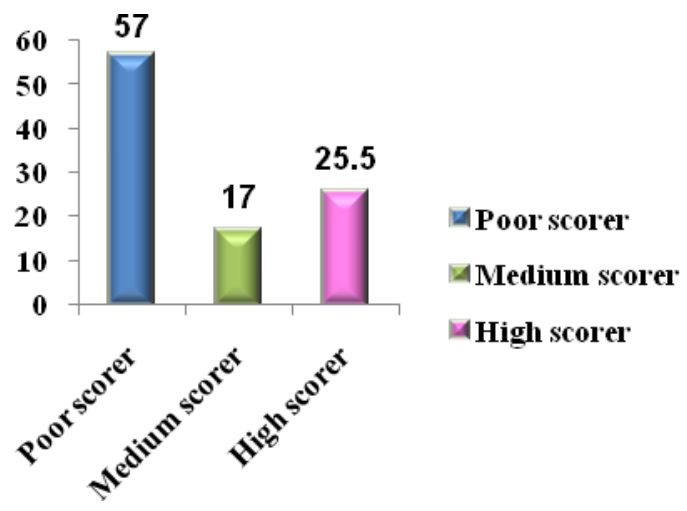

Fig-2. Distribution of respondents by their academic performance in term-I

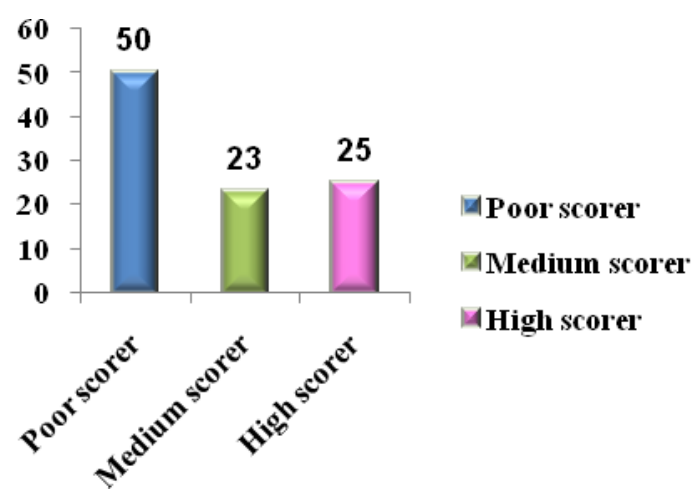

Fig-3. Distribution of respondents by their academic performance in term-II 
Table-1. Distribution of respondents by their extraversion item

\begin{tabular}{|c|c|c|c|c|c|c|c|c|}
\hline \multirow{2}{*}{ Extraversion item } & \multicolumn{2}{|r|}{ DS } & \multicolumn{2}{|c|}{$\overline{\mathrm{DL}}$} & NAND & $\overline{\mathrm{AL}}$ & \multicolumn{2}{|c|}{ AS } \\
\hline & & n $\%$ & $\mathrm{n}$ & $\%$ & $\mathrm{n} \quad \%$ & $\mathrm{n} \quad \%$ & $\mathrm{n}$ & $\%$ \\
\hline Talkative & & 20.0 & 39 & $(19.5)$ & $25 \quad(12.5)$ & $65(32.5)$ & 31 & $(15.5)$ \\
\hline Reserve & 70 & $(35.0)$ & 26 & $(13.0)$ & $25 \quad(12.5)$ & $47(23.5)$ & 32 & $(16.0)$ \\
\hline Full of energy & 8 & $(4.0)$ & 16 & $(8.0)$ & $19 \quad(9.5)$ & $82(41.0)$ & 32 & (16.0) \\
\hline Lot of enthusiasm & 5 & $(2.5)$ & 22 & $(11.0)$ & $23(11.5)$ & $71(35.5)$ & 79 & $(39.5)$ \\
\hline Tends to be quite & 44 & $(22.0)$ & 30 & $(15.0)$ & $31(15.5)$ & $47(23.5)$ & 48 & $(24.0)$ \\
\hline Assertive personality & 4 & $(2.0)$ & 14 & $(7.0)$ & $21(10.5)$ & $63(31.5)$ & 98 & $(49.0)$ \\
\hline Shy and inhibited & 21 & $(10.5)$ & 23 & (11.5) & $19 \quad(9.5)$ & $89(44.5)$ & 48 & $(24.0)$ \\
\hline Outgoing and sociable & 11 & $(5.5)$ & 19 & $(9.5)$ & $28(14.0)$ & $51(25.5)$ & 91 & (45.5) \\
\hline
\end{tabular}

(DS: Disagree strongly; DL: Disagree a little; NAND: Neither agree nor disagree; AL: Agree a little; AS: Agree strongly)

Table- 2. Distribution of respondents by their agreeableness item

\begin{tabular}{|c|c|c|c|c|c|}
\hline \multirow{2}{*}{ Agreeableness } & DS & DL & NAND & $\mathrm{AL}$ & AS \\
\hline & $\mathrm{n} \quad \%$ & $\mathrm{n} \quad \%$ & $\mathrm{n} \quad \%$ & $\mathrm{n} \quad \%$ & $\mathrm{n} \quad \%$ \\
\hline Find fault with other & $76(38.0)$ & $56 \quad(28.0)$ & $29(14.5)$ & $27(13.5)$ & $12(6.0)$ \\
\hline Helpful \& unselfish & $6 \quad(3.0)$ & $(4.0)$ & $18 \quad(9.0)$ & $59(29.5)$ & $109(54.5)$ \\
\hline Quarrel with others & $127(63.5)$ & $26(13.0)$ & $20(10.0)$ & $13(6.5)$ & $14(7.0)$ \\
\hline Forgiving nature & $2(1.0)$ & $(2.5)$ & $14(7.0)$ & $60(30.0)$ & $119(59.5)$ \\
\hline Generally trusting & $2 \quad(1.0)$ & (1.5) & $11 \quad(5.5)$ & $57(28.5)$ & $127(63.5)$ \\
\hline Cold \& aloof & $50(25.0)$ & $32(16.0)$ & $36(18.0)$ & $45(22.5)$ & $37(18.5)$ \\
\hline Cooperates with others & $(2.0)$ & $(0.5)$ & $3 \quad(1.5)$ & $42(21.0)$ & $150(75.0)$ \\
\hline Considerable \& kind & $(1.5)$ & $(3.5)$ & $19(9.5)$ & $5326.5)$ & $118(59.0)$ \\
\hline
\end{tabular}

Table-3. Distribution of respondents by their conscientiousness item

\begin{tabular}{|c|c|c|c|c|c|c|}
\hline \multirow{2}{*}{$\begin{array}{l}\text { Conscientiousness } \\
\text { item }\end{array}$} & \multicolumn{2}{|c|}{ DS } & DL & NAND & $\mathrm{AL}$ & $\mathrm{AS}$ \\
\hline & $\mathrm{n}$ & $\%$ & $\mathrm{n} \quad \%$ & $\mathrm{n} \quad \%$ & $\mathrm{n} \quad \%$ & $\mathrm{n} \quad \%$ \\
\hline Thorough job & 7 & $(3.5)$ & $27(13.5)$ & $7(3.5)$ & $59(29.5)$ & $100(50.0)$ \\
\hline Careless & 43 & $(21.5)$ & $26(13.0)$ & $25(12.5)$ & $82(41.0)$ & $24 \quad(12.0)$ \\
\hline Reliable worker & 7 & $(3.5)$ & $8(4.0)$ & $26(13.0)$ & $50(25.0)$ & $109(54.5)$ \\
\hline Disorganized & 55 & $(27.5)$ & $41(20.5)$ & $23(11.5)$ & $49(24.5)$ & $32(16.0)$ \\
\hline Tends to be lazy & 38 & $(19.0)$ & $33(16.5)$ & $21(10.5)$ & $68(34.0)$ & $40 \quad(20.3)$ \\
\hline Perseveres & 7 & $(3.5)$ & $21(10.5)$ & $23(11.0)$ & $67(33.5)$ & $82 \quad(41.0)$ \\
\hline Does things efficiently & 1 & $(0.5)$ & $13(6.5)$ & $13(6.5)$ & $59(29.5)$ & $114(57.0)$ \\
\hline Makes plan & 12 & $(6.0)$ & $36(18.0)$ & $29(14.5)$ & $63(31.5)$ & $60(30.0)$ \\
\hline Distracted & 56 & $(28.0)$ & $47(23.5)$ & $32(16.0)$ & $50(25.0)$ & $15(7.5)$ \\
\hline
\end{tabular}


Table-4. Distribution of respondents by their neuroticism item

\begin{tabular}{|c|c|c|c|c|c|}
\hline \multirow{2}{*}{ Neuroticism item } & DS & DL & NAND & $\mathrm{AL}$ & AS \\
\hline & $\mathrm{n} \quad \%$ & $\mathrm{n} \quad \%$ & $\mathrm{n} \quad \%$ & $\mathrm{n} \quad \%$ & $\mathrm{n} \quad \%$ \\
\hline Depressed blue & $28 \quad(14.0)$ & $27(13.5)$ & $33(16.5)$ & $63(31.5)$ & $49(24.5)$ \\
\hline Relaxed & $34(17.0)$ & $38(19.0)$ & $21(10.5)$ & $54(27.0)$ & $53(26.5)$ \\
\hline Can be tense & $22(11.0)$ & $41(20.5)$ & $13(6.5)$ & $65(32.5)$ & $59(29.5)$ \\
\hline Worries a lot & $46(23.0)$ & $32(16.5)$ & $21(10.5)$ & $64(32.0)$ & $37(18.5)$ \\
\hline Emotionally stable & $18(19.0)$ & $41(16.5)$ & $25(10.5)$ & $52(34.0)$ & $64(20.5)$ \\
\hline Moody & $48(24.0)$ & $39(19.5)$ & $28(14.0)$ & $59(29.5)$ & $26(13.0)$ \\
\hline Remain calm & $33(16.5)$ & $45(22.5)$ & $18(9.0)$ & $58(29.0)$ & $46(23.0)$ \\
\hline Easily nervous & $35(17.5)$ & $38(19.0)$ & $12(6.0)$ & $62(31.0)$ & $53(26.5)$ \\
\hline
\end{tabular}

Table-5. Distribution of respondents by their openness item

\begin{tabular}{|c|c|c|c|c|c|c|c|}
\hline \multirow[t]{2}{*}{ Openness item } & \multicolumn{2}{|c|}{ DS } & \multicolumn{2}{|c|}{$\mathrm{DL}$} & NAND & $\mathrm{AL}$ & $\mathrm{AS}$ \\
\hline & $\mathrm{n}$ & $\%$ & $\mathrm{n}$ & $\%$ & $\mathrm{n} \quad \%$ & $\mathrm{n} \quad \%$ & $\mathrm{n} \quad \%$ \\
\hline Comes up with new idea & 11 & $(5.5)$ & 9 & $(4.5)$ & $25(12.5)$ & $67(33.5)$ & $88(44.0)$ \\
\hline Curious & 3 & $(1.5)$ & 2 & $(1.0)$ & $22(11.0)$ & $48(24.0)$ & $125(62.5)$ \\
\hline Ingenious & 12 & $(6.0)$ & 24 & $(12.0)$ & $44(22.0)$ & $62(31.0)$ & $58(29.0)$ \\
\hline Active imagination & 36 & $(18.0)$ & 25 & $(12.5)$ & $17(8.5)$ & $56(28.0)$ & $66(33.0)$ \\
\hline Inventive & 13 & $(6.5)$ & 21 & $(10.5)$ & $59(29.5)$ & $62(31.0)$ & $45(22.5)$ \\
\hline Artistic & 1 & $(0.5)$ & 2 & $(1.0)$ & $9 \quad(4.5)$ & $32(16.0)$ & $156(78.0)$ \\
\hline Routine work & 26 & $(0.5)$ & 39 & (19.5) & $21(10.5)$ & $54(27.0)$ & $60(30.0)$ \\
\hline Play with idea & 6 & (3.0) & 26 & (13.0) & $41(20.5)$ & $68(34.0)$ & $59(29.5)$ \\
\hline Few artistic interest & 63 & (31.5) & 35 & (17.5) & $35(17.5)$ & $47(23.5)$ & $20(10.0)$ \\
\hline Sophisticated in art & 17 & $(8.5)$ & 13 & $(23.5)$ & $22(16.0)$ & $57(25.0)$ & $91(45.5)$ \\
\hline
\end{tabular}

Table-6. Pearson coefficient Correlation between five scales of personality and the Students' Academic performance in Term-I and Term-II

\begin{tabular}{lcccc}
\hline & \multicolumn{2}{c}{$\begin{array}{c}\text { Term-I } \\
(\mathrm{n}=200)\end{array}$} & \multicolumn{2}{c}{$\begin{array}{c}\text { Term-II } \\
(\mathrm{n}=200)\end{array}$} \\
\cline { 2 - 5 } Personality type & $r$ & $p$ & $r$ & $p$ \\
\hline Extraversion & -0.107 & 0.134 & -0.103 & 0.150 \\
Agreeableness & 0.046 & 0.523 & 0.034 & 0.639 \\
Conscientiousness & 0.091 & 0.202 & 0.112 & 0.117 \\
Neuroticism & -0.070 & 0.328 & -0.080 & 0.260 \\
Openness & -0.084 & 0.236 & -0.077 & 0.284 \\
\hline
\end{tabular}

$\alpha=0.05$
Table-7. Association between gender and personality types

\begin{tabular}{lcl}
\hline Personality type & $\chi^{2}$ & $p$ \\
\hline Extraversion & 0.178 & 0.724 \\
Agreeableness & 0.064 & 1.00 \\
Conscientiousness & 1.108 & 0.348 \\
Neuroticism & 11.050 & 0.001 \\
Openness & 0.746 & 0.666 \\
\hline
\end{tabular}

$\alpha=0.05$

\section{Discussion}


This cross sectional descriptive study was carried out among the second year dental student of three non-governments and one government dental college. From these study analyze the findings that was reveal were personality characteristics of dental student and their academic performance, level of academic performance of student in term-I and term-II and association between personality five factors and gender

Dental students high in extroversion appear to experience less difficulty in clinical components of their dental programs compared to introverts who experience less difficulty in the academic components of the program. ${ }^{12}$ However, parallels can be drawn between this research and others, all were discuss about extraversion that introverts would have an advantage over extraverts with respect to the ability to consolidate learning, as well as lower distractibility and better study habits. ${ }^{13}$ Furthermore, it is also likely that Introversion rather than Extraversion may be advantageous for knowledge acquisition, possibly due to the fact that introverts spend more time studying alone than extraverts. ${ }^{14}$

This study shows negative correlations of extraversion scale that means those who were extraverted their result were poor but not statistically significant.This study was also consistent with the findings of Rolfhus and Ackerman who reported negative correlations between Extraversion and several knowledge tests, and suggested that these correlations may be a consequence of differences in knowledge acquisition time between introverts (spend more time studying) and extraverts (spend more time socializing). ${ }^{14}$

Chamberlain et al also found that Extroversion was not associated with any performance measure. ${ }^{15}$ Goff and Ackerman find negative correlations between Big-Five factor Extraversion and both undergraduate and high-school GPA. ${ }^{16}$

This study shows positive correlations of Agreeableness scale but not statistically significant that means those who were possess agreeableness criteria their result were good.

The association between Agreeableness and GPA was also strongest in elementary school and decreased later. As the correlations were decreasing smoothly from Grade 2 to Grade 12, there seems to be a reason to attribute this decrease to age, not just to the change of instrument. Although direct links to learning outcomes are hard to find for Agreeableness, emphasized its role in maintaining good relations with teachers and classmates, which leads to better academic adjustment over the course of development. ${ }^{17}$
Table6. shows positive correlation between Conscientiousness and both term examination and not statistically significant. The relationship between Conscientiousness and academic performance has been the focus of several recent studies. Chamberlain et al $(2005)^{15}$ their results provide strong evidence for the use of Conscientiousness and its facets in the selection of dental students. Students who score high in conscientiousness are more likely to perform better in both their clinical and academic courses and to receive higher assessments with respect to professionalism. Their regression analyses further supported the importance of Conscientiousness and its facets as predictors of dental school performance. Conscientiousness and its facet of Deliberation significantly improved upon the prediction of professional behavior that could be made from the DAT component of Perceptual Ability.

At 2007 Amanda et al studied on three academic year of one dental school and the results of their study support the use of the FFM of personality in dental admissions. Conscientiousness predicted academic or clinical performance or both in every year of dental training. These results are in line with previous research on the role of conscientiousness in predicting different aspects of job performance across many occupations their study confirms these findings for dental students. Those students who are more conscientious demonstrate higher levels of performance than students who are less conscientious both in the classroom and in the clinic and throughout their tenure in dental school. ${ }^{18,19}$

The relationship between academic performance and Neuroticism is usually understood in terms of anxiety, particularly under stressful conditions such as university examinations. Furthermore, researchers have noted that Neuroticism may also impair performance on psychometric intelligence tests. ${ }^{19}$

Studies have also shown that neurotic students have a greater tendency to be absent in examinations due to medical illness or to request, and require, "special treatment", 18

From a psychological point of view, it has been shown that Neuroticism is related to low selfestimated intelligence. $^{18}$

Table 6 shows negative coefficient correlation between Openness scale that means those who were possesses openness their result were poor in two term examination but score not statistically significant

In contrary of this finding previous research suggested that Openness might not be a 
characteristic suited to the dental environment, which requires students to follow established procedures. This environment would not be favorable for students who were more creative; rather, students who were more comfortable using established methods and techniques would be more successful. However, recent changes in dental education have focused on more problem-based learning, and those students who are more intellectually curious may be doing much better in those environments.

Chamberlain et al. found openness to Experience did not predict any of the criterion measures, but its narrow facets of Actions $(r=0.22)$, preferring novelty to the routine, predicted first-year performance while Ideas $(r=0.26)$, being intellectually curious, predicted professional behavior. ${ }^{15}$ Smithers et al. found that Openness to Experience was negatively correlated with the coursework criteria, as was the Ideas facet. These differences with respect to Openness to Experience may reflect differences between the participants in two studies. ${ }^{20}$

Reason of this poor performance might be due to their low IQ or low understanding level. They might be not grasping their concentration in the classes or unmotivated in the academic area. Nonanxious learners with low IQ and able learners who are highly anxious are equally handicapped in academic settings.

From the result regarding category of Extraversion, Agreeableness, Conscientiousness and Openness (Table 7) Pearson chi-square test was statistically not significant. But regarding category of Neuroticism analysis of the data indicates that majority of students were female who had neurotic type of personality. Pearson chi-square test was statistically significant.

From the above findings it was clear that there was no significant association between gender and personality factors except neuroticism. This may reflect characteristics of some female student who might be perceive dental college as a hostile environment. Smithers et al. found females were higher in terms of Agreeableness $(r=.14, p<.05)$, Neuroticism $(\mathrm{r}=.28, \mathrm{p}<.01)$, and Openness $(\mathrm{r}=.17$, $\mathrm{p}<.05) .^{20}$ This finding coordinates with a study by Chamberlain et al a significant relationship between gender and neuroticism $(r=.45)$ deserves comment. This correlation suggests that female students were more anxious, self-conscious, and vulnerable than their male colleagues. ${ }^{15}$
When possible, dental students should be offered multiple learning opportunities that promote motivation and allow for an expression of preference. Educating students on individual personality types would help them to better understand their own behavior, the behavior of others, and the most effective way to interact with others. Implications would include student/student, student/faculty, student/patient, and ultimately dentist/patient relationships. An appreciation for and application of type by both faculty and students would not only contribute to the effectiveness of any clinical curriculum, but should also produce a more competent, effective, and content practitioner. According to the findings of this study the suggestions are:

1. Extraversion, neuroticism and openness had negative correlation with academic performance though it was not statically significant so, for better performance afore mention factors should be minimize as much as possible.

2. Teacher should consider different personality trait of the student adapt teaching learning session accordingly.

3. Neuroticism among female students may be reduced by creating non-threatening teaching learning session.

4. Further studies may be carried out with larger representative samples for drawing definitive conclusion.

\section{Conclusion}

From the point of view of findings of this study it can be concluded that there was no relationship between personality characteristics of dental students and their academic performance. It might be whether an individual will excel or fail in academic settings seems to depend on his/her hard work rather than theirs personality. Furthermore it can be said that personality variables will be related to academic success when the characteristic modes of behavior of student play a role in academic performance.

\section{Recommendations}




\section{References}

1. Brown, R.K. (1930). Research in the use of a rating scale as a means of evaluating the personalities of senior dental students'. J Dent Res 10, 271.

2. O'Connor, M.C. and Paunonen, S.V. (2007). Big Five personality predictors of post-secondary academic performance. Personality and Individual Differences 43, 971-99.

3. Walton, H.J. (1987). Personality assessment of future doctors: a discussion paper. Joum1 of the Royal Society of Medicine 80, 27-30.

4. Crisp, A.H. (1984). Selection of medical students: is intelligence enough? Journal of the Royal Society of Medicine 77, 35-9.

5. Bartnick, L.W., Kappelman, M.M., Berger, J.H. \& Sigman, B. (1985). The value of the CPI in Predicting medical students' career

6. Huxham, G.J. (1980). Achievement factors and personality in a cohort of medical students. Medical Education 14, 97-108.

7. Hobfoll, S.E., Anson, 0. and Antonovsky, A. (1982). Personality factors as predictors of medical student performance. Medical Education 16, 251-8.

8. Aldrich, C.K. (1987). Psychiatric interviews and psychological Tests as predictors of medical students' success. Journal of Medical Education 62, 658-84.

9. Weiss, M., Lotan, I., Kedar, H. \& Ben-Shakhar, G. (1988). Selecring andidates for a medical school: an evaluation of a selection model based on cognitive and personality predictors. Medical Education 22, 492-7.

10. Pallegama, R.W., Ariyasinghe, S. and Perera, H.A.E.D. (2007). Influence of Personality Traits on the Attitudes Towards the Teaching Program and the Academic Performance of Dental Undergraduates Proceedings of the Peradeniya University Research Sessions, Sri Lanka, Vol.12, Part I, 30 ${ }^{\text {th }}$ November

11. John, O. P., and Srivastava, S. (1999). The Big Five trait taxonomy: History, measurement, and theoretical perspectives. In L. A. Pervin \& O. P. John (Eds.), Handbook of personality: Theory and research (2nd ed., pp. 102-138). New York: Guilford.

12. Jone,s A.C., Courts, F.J., Sandow, P.L., and Watson, R.E.(1997). Myers Briggs Type Indicator and dental school performance. J Dent Educ 61(12), 928-33.

13. Furnham, A., and Chamorro-Premuzic, T. (2004). Personality and intelligence as predictors of statistics examination grades. Personality and Individual Differences 37, 943-955.

14. Rolfhus, E., \& Ackerman, P. L. (1999). Assessing individual differences in knowledge: Knowledge, intelligence, and related traits. Journal of Educational Psychology, 91, 511-526.

15. Chamberlain, T.C., Catano, V.M. and Cunningham, D.P. (2005). Personality as a Predictor of Professional Behavior in Dental School: Comparisons with Dental Practitioners. Journal of Dental Education 69,1222-1237.

16. Goff, M., and Ackerman, P. L. (1992). Personalityintelligence relations: Assessment of typical intellectual engagement. Journal of Educational Psychology 84, 537552 .

17. Busato, V. V., Prins, F. J., Elshout, J. J., \& Hamaker, C. (2000). Intellectual ability, learning style, achievement motivation and academic success of psychology students in higher education. Personality and Individual Differences, 29, 1057-1068.

18. Amanda, P., Victor, M., Catano, V.M. and Cunningham, D.P. (2006). Predicting Performance in Canadian Dental Schools: The New CDA Structured Interview, a New Personality Assessment, and the DAT. Journal of Dental Education 71,664-676.

19. Furnham, A., Chamorro-Premuzic, T., McDougall, F. (2003). Personality, cognitive ability, and beliefs about intelligence as predictors of academic performance. Learning and Individual Differences 14, 49-66.

20. Furnham, A., and Chamorro-Premuzic, T. (2004). Personality and intelligence as predictors of statistics examination grades. Personality and Individual Differences 37, 943-955.

21. Smithers, S., Catano, V.M., \& Cunningham, D.P. (2004). What Predicts Performance in Canadian Dental Schools. Journal of Dental Education 68, 598-613. 